\title{
Discussion on Promoting the Competitiveness of Chinese Enterprises' Marketing
}

\author{
Jin Du \\ Yinxing Hospitality Management College, Chengdu University of Information Technology, Chengdu \\ Sichuan, 611743, China
}

Key words: Enterprise, Marketing, Competitiveness.

\begin{abstract}
Today, China's economic and social development has been extremely rapid period, but in fact a large number of enterprises in China's product marketing system there are still considerable limitations, so that many products sales problems, the lack of significant marketing performance. China's modern enterprises in order to be able to under the brutal laws of market competition under the very large development, it should be based on the development of the market, the use of more effective measures to enhance the market share of enterprises, thereby enhancing the competitiveness of enterprise marketing. This paper gives an overview of the marketing competitiveness of enterprises, discusses the distinctive characteristics of the marketing competitiveness of enterprises, analyzes the problems existing in the marketing competitiveness of Chinese enterprises, and puts forward some countermeasures to enhance the marketing competitiveness of Chinese enterprises.
\end{abstract}

\section{Introduction}

In view of China's industrialization is moving in a more mature direction to develop, the same type of product quality and performance, service and other aspects of the degree of thinking has become increasingly high, the market competition system has become increasingly white-hot. For enterprises, just by improving the quality and function of goods has been unable to become a greater benefit of the enterprise approach, with a larger market share of the product is easy for other enterprises imitation, which in a considerable extent to enhance Conflict between enterprises, and not the same supply companies to provide the same category of products will also be caused by the customer can not distinguish the difference between the interests of the difference. So, more companies have realized that the singular brand competition can not make themselves in the competition to win. Only more reasonable use of marketing tools to get the customer's consumer demand. In view of this, to enhance the core competitiveness of China's corporate marketing is extremely important.

\section{An Overview of Enterprise Marketing Competitiveness}

The so-called marketing, mainly refers to the individual and collective use to create, provide and exchange the value of the product with the social and management process. In the current enterprises in China, the enterprise marketing competitiveness can be understood as the enterprise based on their own marketing situation and resource conditions, the implementation of systematic marketing, which in the current market competition which have a comparative advantage to create a corresponding customer value to mutual benefit Reciprocal approach to the implementation of business and stakeholders. Nowadays, more and more research in academia also confirms that the important basis for the survival and development of enterprises has been the core competitiveness, and the most essential factor in generating core competence is marketing. 


\section{The distinctive characteristics of enterprise marketing competitiveness}

\section{With integrated features}

Marketing competitiveness does not mean that the enterprise has a single marketing assets, elements or enterprises to carry out a marketing activities of the ability, but includes the enterprise's overall marketing management process, not only contains the enterprise for all kinds of marketing activities Overall planning, organization, coordination, but also covers the enterprise's marketing structure, management and corporate resources and other factors closely integrated results. Its formation requires its business and human resources, finance and production management and many other management functions to cooperate and coordination. Therefore, the marketing competitiveness can be said that the enterprise brings together their various elements and capabilities arising from the overall management capacity.

\section{With value features}

Mainly includes the following three aspects: First, customer value marketing competitiveness should be customer-oriented, which is the obvious characteristics of marketing competitiveness. Only to continue to create the corresponding value for customers, companies can get better development. Therefore, in order to improve the competitiveness of enterprise marketing, we must create a corresponding value for the customer, and let it be satisfied. Second, the value of enterprise marketing competitiveness should be the enterprise application of its resources and ability to better meet the actual needs of the market to grasp the market competitiveness of a comprehensive ability. It must be able to continue to improve the overall marketing ability of enterprises and the positive use of marketing opportunities, so as to provide enterprises with more significant competitive advantage, and effectively enhance the business of all kinds of tangible and intangible value. Third, the social value of marketing competitiveness is not only an important link between enterprises and the market, but also among the production and business activities to achieve an important guarantee for foreign economy. Therefore, from the perspective of economics, enterprises in the marketing management of the advantages of the promotion of social welfare is very good.

\section{Problems in Marketing Competitiveness of Chinese Enterprises}

\section{Part of the business management concept is lagging behind}

At present, some enterprises in China in the implementation of various marketing activities, or by the previous planned economic system left by the impact of the lack of the buyer's market demand for the full analysis of the marketing concept is still lagging behind, and even still out of date The production and product concept to implement marketing activities. In view of the continuous improvement and perfection of the market economy mechanism with Chinese characteristics, the market environment faced by our enterprises is becoming more and more complicated and changeable. China's enterprises in its production and operation of the process, if still satisfied with the traditional means of marketing, then naturally can not effectively meet the actual needs of enterprises. At present, a large number of enterprises in the implementation of marketing activities in the process, although considerable emphasis on the performance of marketing work, but to a considerable extent, ignoring the products provided by the after-sales service; although still pay more attention to marketing workers singles But it ignores the collaboration between the marketing staff, the marketing department and the other departments.

\section{Part of the enterprise's marketing strategy is not distinctive features}

Enterprises in marketing, the rational application of marketing strategies can effectively improve the enterprise's marketing competitiveness. However, a large number of enterprises in the implementation of marketing activities in the process, or not able to effectively and effectively based on their actual situation, to develop a business strategy to meet the future development of the 
enterprise, so that corporate marketing to enhance the characteristics of the intention. At present, due to the continuous development of China's reform and opening up business, and promote the sustainable development of China's foreign trade system, but also to our market is facing increasing domestic and international dual market competition, the enormous pressure. If the enterprise can not according to their own characteristics to develop the correct market sales countermeasures, it is difficult in the increasingly fierce competition in the market which better survival and development.

\section{Part of the enterprise's marketing approach to control their own further development}

In the growing tide of competition in the market, some of our enterprises failed to their own development as an objective and accurate understanding of the current market can not be implemented with a strong operational research, so that can not really To understand the actual needs of customers, can not effectively respond to a variety of changes in the market, it is unable to develop a reasonable to promote the development of enterprises related countermeasures. In the implementation of marketing, some companies only rely on the packaging of products and some of the staff of the marketing staff to implement the individual, so that the lack of sales of the vitality of the work. Once the enterprise products appear slow-moving phenomenon, will continue to depress the price of their products, resulting in the interests of many enterprises suffered losses, resulting in enterprises can not get better development.

\section{Some Measures to Improve the Competitiveness of Chinese Enterprises' Marketing}

\section{To guide enterprises to form a new concept of marketing}

For the enterprise, the appropriate marketing idea is its prerequisite for doing a good job in sales. In view of this, companies should pay close attention to the concept of marketing innovation at the level. In fact, the marketing concept will continue to change as the market continues to evolve with the company's development goals. Enterprises should effectively change the traditional sense of the marketing concept, the formation of the enterprise's products, service quality as the main body, while the price competition to support the new concept of marketing. Enterprises should shift the competition to the field of non-price competition, mainly the use of product types, quality, patents and characteristics, packaging and other market promotion activities to enhance the purchasing power of the vast number of consumer groups to promote the purchase of consumer groups more The product. Of course, companies also provide customers with good enough after-sales service, which continued to improve the sales of enterprises in the market.

\section{Continuous improvement of the company's sales methods}

Modern enterprises in the promotion of marketing process, the product sales methods directly affect the company's total product sales. Therefore, enterprises in the implementation of marketing activities in the process, to effectively improve the marketing strategy, pay more attention to the application of information technology, to adopt more scientific information technology means to update the type of enterprise products, so as to better meet the majority of consumption The masses of the various needs. Of course, enterprises should also make proper use of modern network economy, and earnestly grasp the contemporary consumer groups have more personalized needs, so as to timely for the consumer groups to provide better service. Of course, enterprises should also make full use of the network with the high efficiency, to develop a practical product prices, so that consumers can immediately see the most competitive product prices, and then allow consumers to implement specific consumer behavior.

\section{The use of differentiated sales means to enhance the competitiveness of products}

Enterprises to implement marketing means are able to effectively promote the company's product sales and the implementation of the initiatives, which mainly covers the product sales and corporate image marketing and so on. Its final goal is to do a reasonable flow of funds and products between the 
operation. China's enterprises should be based on their own reality, through the operation of the market in the form of enterprises based on the actual situation, the introduction of differentiated sales, effectively promote the enterprise to achieve the competitiveness of marketing continue to improve. First, to promote the refinement of the enterprise market. To achieve the market can be said that the refinement of enterprises to enhance their own products, an important basis for marketing competitiveness. Today, China's various sectors of the market competition has become increasingly fierce, increasing the number of peer companies, product technology has become increasingly complex. At the same time, corporate competitors are not only domestic enterprises, but also foreign counterparts to compete. Therefore, our enterprises must be based on their actual situation, effectively play the advantages of all aspects of the enterprise, for the specific target market implementation of the enterprise production, management and sales business activities. To give full play to the products have all kinds of advantages, the use of branding effect, the enterprise will really develop the authority of the industry enterprises. Second, do a good job of product positioning. At present, China's enterprises should be a comprehensive understanding of the premise of the market under the premise of a reasonable understanding of production capacity. Once the lack of production capacity, or although the production capacity, but the product is not competitive enough. In this way, the implementation of the market will become impossible to complete the task. In view of this, enterprises should take the target market as a prerequisite to fully explore the development potential of enterprises. In the technical improvement and innovation, should continue to improve production efficiency to the needs of the market. Enterprises in the production, once can not be a positive practice, continuous innovation, its competitiveness in the marketing process naturally can not be improved. If the enterprise can be based on the general product to enhance the other subsidiary function, so that naturally can greatly improve the competitive strength of the enterprise. Third, continue to improve the quality of service, which can be said to enhance product marketing competitiveness of one of the basic aspects. Now the essence of competition between Chinese enterprises is the service level of competition, especially the various types of products have their own functions, quality and other very similar circumstances, the service has become the customer to select the enterprise products, an important standard in the In this case, the difference between marketing means has become the enterprise products can stand out in the competition an important indicator. Enhance the marketing competitiveness of the essence of the product is to improve the enterprise's service capabilities. In the normal operation of the enterprise, we should effectively implement the concept of providing first-class service to customers. Service is not just the work of enterprise marketing agencies, but should run through the enterprise product design, production of the links, which show the principle of customer first. Only in this way, enterprises can produce high-quality products, the majority of customers by the heart of recognition, and thus for the sustainable development of enterprises lay a good foundation.

\section{And consistent enhance the competitiveness of corporate culture level}

Corporate culture can be said to be an important spiritual pillar of the enterprise, which plays an extremely important role in the marketing process. Therefore, enterprises in the specific marketing practice, we should strive to do the following two aspects of work: on the one hand is to continue to strengthen the staff for the group deeply felt the corporate culture and to identify, so that the majority of employees into the marketing At the time of work, the company can be the most elite of the cultural connotation in full display in front of customers, so that it can understand and appreciate the culture of the enterprise, so peace of mind to buy the company's products. On the other hand is the enterprise to be based on the current marketing environment of continuous change, and constantly improve their own corporate culture of the content, with the development of enterprises, the increase in products, employees continue to enrich and extend the enterprise's cultural connotation, Effectively improve the hard power of corporate culture. Only in this way can we continue to enhance the competitiveness of corporate culture, so that the enterprises can get more orders, so as to be able to continuously improve their market competitiveness. 


\section{Conclusions}

To sum up, China's enterprises in order to become increasingly fierce competition in the modern market which is invincible, it should be to ensure that the quality of enterprise products on the basis of China's market development based on the actual situation, more flexible response And solve the problems arising from the marketing of enterprises, and actively use the positive and effective to further enhance the competitive strength of the market sales strategy, so as to expand a broader market for enterprises to promote China's enterprises to achieve sustainable development.

\section{References}

[1] Zheng Changhong. How to improve the marketing ability of enterprises and enhance the competitiveness of enterprises, China Science and Technology Investment 2012 (26).

[2] Qin Yi. Marketing core and the key point of customer management, Talent and business, 2013 (6).

[3] Sheng Xiaoyan. How to do the innovation of enterprise marketing, Shopping modernization, 2014 (25).

[4] Huang Yuan. How to improve the competitiveness of marketing,Chinese and foreign entrepreneurs, 2015 (28).

[5] Qi Ruiwen. On China's automobile manufacturing enterprises marketing competitiveness evaluation, Modern Economic Information, 2016 (22). 